\title{
Detection of groundwater storage variability based on GRACE and CABLE model in the Murray-Darling Basin
}

\author{
Tongqing $\mathrm{Li}^{1}$, Qibin Zhang ${ }^{1}$, Yueyao Zhao ${ }^{1}$, and Yuanbin $\mathrm{Gao}^{2}$ \\ ${ }^{1}$ Shandong University of Science and Technology, College of Geomatics, 266590 Qingdao, China \\ ${ }^{2}$ China Railway Shanghai Bureau Group Co. Ltd. Ningbo Works Section, 315000 Ningbo, China
}

\begin{abstract}
Monitoring groundwater storage is in great importance for economic and social development. In this paper, the monthly GRACE data from 2003 to 2015 is combined with the Community Atmosphere Biosphere Land Exchange (CABLE) model to estimate the variations of groundwater storage (GWS) in the Murray-Darling Basin (MDB). The results show that (1) the simulations of TWS from CABLE are more accurate than GLDAS over the MDB, and there is a higher correlation coefficient of 0.94 and a lower RMSE of 15.74 between CABLE and GRACE. (3) The spatial pattern of GWS trends shows decline trends in the southwest, east and south, and increasing trends in the north and south central (3) For the whole MDB, the average GWS has strong seasonality and shows an increasing trend with a rate of $1.19 \pm 0.41 \mathrm{~mm} /$ year between 2003 and 2015.
\end{abstract}

\section{Introduction}

As the largest freshwater storage component of global hydrological cycle, groundwater is a basic resource for human life, and agriculture and industry [1]. Monitoring groundwater storage changes is crucial for economic development and resource management. However, traditional groundwater monitoring methods which are based primarily on ground-based observations are difficult to comprehensive understand the spatial and temporal variation of groundwater due to the limits of data gaps and large errors.

The Gravity Recovery and Climate Experiment (GRACE) gravity satellite mission present a new way to monitor the change of the groundwater storage (GWS) with unprecedented accuracy [2]. The GRACE can sense the terrestrial water storage anomalies (TWSA) by measuring the time-varying gravitational field of the Earth [3]. The TWSA is the total change of all water components, including groundwater, snow water equivalent (SWE), soil moisture (SM) and surface water [4]. Therefore, after subtracting the changes of the other components from TWSA, the GWS changes can be obtained. In general, the SWE and SM can be simulated from hydrological models such as GLDAS, W3RA and WGHM, of which the GLDAS is the most commonly model. In recent years, there have been many studies of the retrieval of groundwater changes in different regions using the GRACE satellite gravity data and hydrological models, e.g., Mississippi River basin, the North China Plain, Amazon Basin [5-7].

The Community Atmosphere-Biosphere Land Exchange model (CABLE) is a land surface model (LSM) that can be applied in stand-alone applications and also provides for land surface-atmosphere exchange within the Australian Community Climate and Earth System Simulator (ACCESS) [8]. The simulations from the CABLE model has been proved to be very reliable on Australian and global scale [9-10]. Therefore, the output data from CABLE model can provide accurate information of surface water and flux field such as SWE and SM like other hydrological models. Several studies have applied this model to estimate the GWS changes combining with GRACE data [11].

This paper aims to evaluate the reliability of CABLE and analyze the GWS variations estimated by GRACE and CABLE model over Murray-Darling basin during 20032015. Firstly, the reliability of simulations from CABLE are verified by comparing with GRACE and GLDAS. Then, the temporal and spatial variations trends of the groundwater are analyzed. The results should allow researchers to use the CABLE model as an alternative in applications of groundwater monitoring, and can provide references for understanding GWS changes in MurrayDarling basin and making reasonable responses.

\section{Study area}

The Murray-Darling Basin (MDB) region covers more than 1,000,000 km2, one-seventh of mainland Australia, sitting in southeastern Australia (see Fig.1). The topography of the MDB is dominated by vast plains, bounded to the east and south by the Great Dividing Range that has undulating hills reaching an elevation of up to $2200 \mathrm{~m}$ above sea level.

There is a wide range of climatic conditions in the MDB that follow north- south and east- west gradients. In 
the eastern uplands (Great Dividing Range), the climate varies from temperate in the south to mountainous and subtropical in the north. The vast plains of the west, which occupy most of the MDB, have a hot semi- arid to arid climate. Rainfall is summer dominated in the north and winter dominated in the south [12]. Annual rainfall ranged from more than $1,200 \mathrm{~mm}$ in the southeast to less than 200 $\mathrm{mm}$ in some areas across the southwestern part of the region. The MDB is essentially a closed groundwater basin, where groundwater drainage is directed internally towards the central subsidence and thicker sediments, rather than towards the side where the Murray connects to the sea [13].

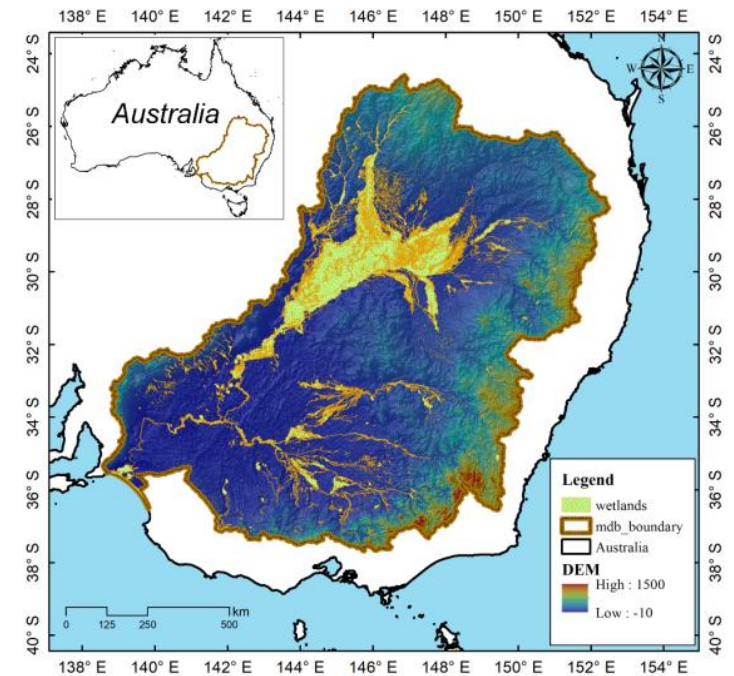

Fig.1. Location and digital elevation map of Murray-Darling Basin, Australia.

\section{Datasets and methods}

\subsection{Datasets}

\subsubsection{GRACE-derived TWS data}

To evaluate the monthly GRACE-derived TWS variability, newly released GRACE mascon (mass concentration) solutions (version RL05) from the Center for Space Research are used. The monthly TWSA data, with a spatial resolution of $0.5^{\circ} \times 0.5^{\circ}$, can be obtained from https://grace.jpl.nasa.gov/data/get-data/monthly-massgrids-land/. These solutions are constrained by a timevariable regularization matrix and are derived only from GRACE information; no external models or data are used to inform the constraints. There resulting mascon has no visible stripe errors and can capture signals well observed by GRACE within the measurement noise level comparing with traditional spherical harmonic approach [14-15].

\subsubsection{Hydrological models -simulated SMS and SWE data}

CABLE is a publicly available land surface model and can be used to simulate SMS and SWE as well as groundwater in terms of volumetric water content every $3 \mathrm{~h}$ at a $0.5^{\circ} \times 0.5^{\circ}$ spatial resolution. The CABLE simulates soil moisture in six different layers with the depths of 0.022 , $0.058,0.154,0.409,1.085$ and $2.872 \mathrm{~m}$, from top to bottom, respectively [11]. More details about the CABLE model refer to [16-17].

The Global Land Data Assimilation System (GLDAS) is also used to compare to CABLE. GLDAS is jointly developed by the National Aeronautics and Space Administration (NASA) and the National Oceanic and Atmospheric Administration (NOAA) [18]. In this study, the latest Noah 2.1 model of monthly soil moisture, snow water equivalent and plant canopy surface water from 2003 to 2015 on a $0.25^{\circ} \times 0.25^{\circ}$ spatial resolution are utilized, then resampled to $0.5^{\circ} \times 0.5^{\circ}$ grid resolution. SM in Noah2.1 model is divided into four layers, 0-0.10, 0.10$0.40,0.40-1.00$, and $1.00-2.00 \mathrm{~m}$, respectively.

The above time-series data were selected from January 2003 to December 2015, and the missing values are interpolated through the cubic-spline method. In order to calculate the monthly anomalies of those data, the mean values (from January 2004 to December 2009) are removed from the monthly values.

\subsection{Methods}

\subsubsection{Estimation of GWS from GRACE TWS}

The TWSA measured by GRACE are the total water variations, including groundwater storage (GWS), soil moisture (SM), snow a water equivalent (SWE) and surface water storage (SWM) [4]. Therefore, after subtracting other components, the groundwater variations can be estimated by the following formula:

$$
\Delta G W S=\Delta T W S-\Delta S M-\Delta S W E-\Delta S W M
$$

Where $\triangle G W S$ is the GWS variations, $\triangle T W S$ is the variations of total water storage from GRACE, $\triangle S M$, $\triangle S W E$ and $\triangle S W M$ are variations of soil moisture, snow water equivalent and surface water storage, respectively, and they can be acquired from CABLE and GLDAS.

\subsubsection{Multiple Linear Regression (MLR) Analysis}

The combination of MLR and Least Squares Approach (LSA) was commonly employed in time series to evaluate the differences among the different variables [19]. In this paper, the trend and annual components of each time series are modeled by a regression model, which can be expressed as:

$$
\begin{aligned}
& X(t)=\beta_{1}+\beta_{2} t+\beta_{3} \sin \left(\frac{\pi t}{6}\right)+\beta_{4} \cos \left(\frac{\pi t}{6}\right) \\
& +\beta_{5} \sin \left(\frac{\pi t}{3}\right)+\beta_{6} \cos \left(\frac{\pi t}{3}\right)+\varepsilon
\end{aligned}
$$

where $\mathrm{X}(\mathrm{t})$ is the time series of TWS, and $\beta_{1}, \beta_{2}$, $\beta_{3}, \beta_{4}, \beta_{5}$ and $\beta_{6}$ are the constant offset, linear trend, annual signals $\left(\beta_{3}\right.$ and $\left.\beta_{4}\right)$, and semi-annual signals $\left(\beta_{5}\right.$ and $\beta_{6}$ ), respectively. $\varepsilon$ represents the model bias and/or 
data error. Then, the annual amplitude (A) and annual phase $(\mathrm{P})$ of the time-series datasets were written as Equation (3) and (4), respectively.

$$
\begin{array}{r}
A=\sqrt{\beta_{3}^{2}+\beta_{4}^{2}} \\
P=\arccos \left(\beta_{3} / A\right)
\end{array}
$$

\section{Result and discussion}

\subsection{Comparison of TWS variations from GRACE, CABLE and GLDAS}

TWS variations derived from CABLE, GLDAS and GRACE are compared to indirectly evaluate the accuracy of CABLE model. The GRACE data is used as a criterion due to its respectively high accuracy. Fig. 2 shows the monthly time series of the average TWS variations from GRACE (black line), CABLE (red line with circle) and
GLDAS (blue line with triangle) over the MDB from 2003 to 2015. It can be seen that the three time-series are basically consistent, and showing the same trend at any period. However, CBALE tends to be closer to GRACE than GLDAS. There are significant differences between GRACE and GLDAS, especially from 2003 to 2005 and from 2010 to 2011.

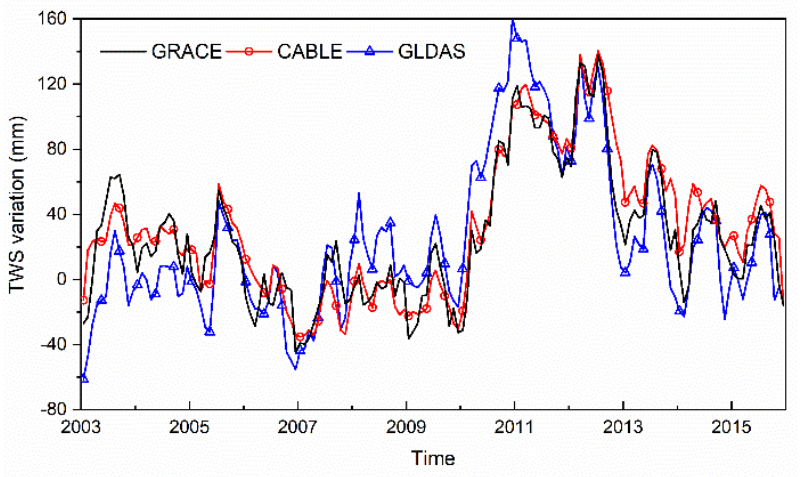

Fig.2. Time series of TWS from GRACE, CABLE and GLDAS over MDB from 2003 to 2015.

\begin{tabular}{|c|c|c|c|c|c|}
\hline \multirow{2}{*}{ Datasets } & \multicolumn{2}{|c|}{ Annual } & \multirow{2}{*}{$\begin{array}{c}\text { Trend } \\
\text { (mm/year) }\end{array}$} & \multirow{2}{*}{$R$ with GRACE } & \multirow{2}{*}{$\begin{array}{c}\text { RMSE with } \\
\text { GRACE }(\mathbf{m m})\end{array}$} \\
\hline & Amplitude (mm) & Phase $\left(^{\circ}\right)$ & & & \\
\hline GRACE & 18.00 & 204.50 & $3.49 \pm 0.84$ & -- & -- \\
\hline GLDAS & 9.65 & 187.77 & $4.84 \pm 0.95$ & 0.89 & 19.27 \\
\hline CABLE & 11.29 & 192.42 & $4.23 \pm 0.82$ & 0.94 & 15.74 \\
\hline
\end{tabular}

Table 1. Comparison of TWS from GRACE, CABLE and GLDAS in patterns of amplitude, phase and trend.

Table 1 indicates that CABLE is closer to GRACE than GLDAS in all patterns of amplitude, phase and long-term trend. Moreover, the correlation coefficient (R) and the Root Mean Squared Error (RMSE) are used to evaluate the difference between two time series. There are a higher correlation coefficient and a lower RMSE between CABLE and GRACE, with the values of 0.94 and 15.74 $\mathrm{mm}$, while with the values of 0.89 and $19.27 \mathrm{~mm}$ between GLDAS and GRACE, respectively. Those values indicate that the simulations from CABLE are more reliable than GLDAS over the MDB. The reasons for the respectively low accuracy of GLDAS may be the followings: (1) the SM from GLDAS is not as details as that from CABLE; (2) SWM from GLDAS does not consider storage in lakes and reservoirs [20-21]. Therefore, we use the CABLE to describe the characteristics of SM and SWE variations.

\subsection{Spatial and Temporal variations of GWS based on GRACE and CABLE}

Based on Equation (1), regional estimates of changes in GWS are obtained by subtracting variations of SM and SWE as well as SWM from the TWS time series. The spatial pattern of GWS trends estimated from GRACECABLE for MDB from 2003-2015 is shown in Figure 3. The most obvious negative trend is mainly located in the northwest (D1), east (D2) and north (D3) with the average rates of $-1.44 \mathrm{~mm} /$ year, $-2.11 \mathrm{~mm} /$ year and $-4.32 \mathrm{~mm} /$ year respectively, while the positive trends is mainly located in the north (R1) and south central (R2) with the average rates of $3.48 \mathrm{~mm} /$ year and $2.87 \mathrm{~mm} /$ year. The reasons for the negative or positive trends of GWS in those areas are primarily rainfall decline or increase, respectively.

Figure 4 shows the time series of average GWS variation for the whole region. It indicates that: time series of GWS behavior a strong periodicity and seasonality with increase in autumn and winter and decline in spring and summer, the main reason is that there is more rainfall in autumn and winter and less in spring and summer. The GWS anomalies also indicate a strong and continuous decline during 2003 to 2010 with the slope of $-6.31 \pm 0.75$ $\mathrm{mm} /$ year and an increasing trends in recent years with the slope of $2.21 \pm 0.66 \mathrm{~mm} /$ year (Figure 4). For the period 2003-2015, the GWS variation has an increasing trend with a rate of $1.19 \pm 0.41 \mathrm{~mm} /$ year. 


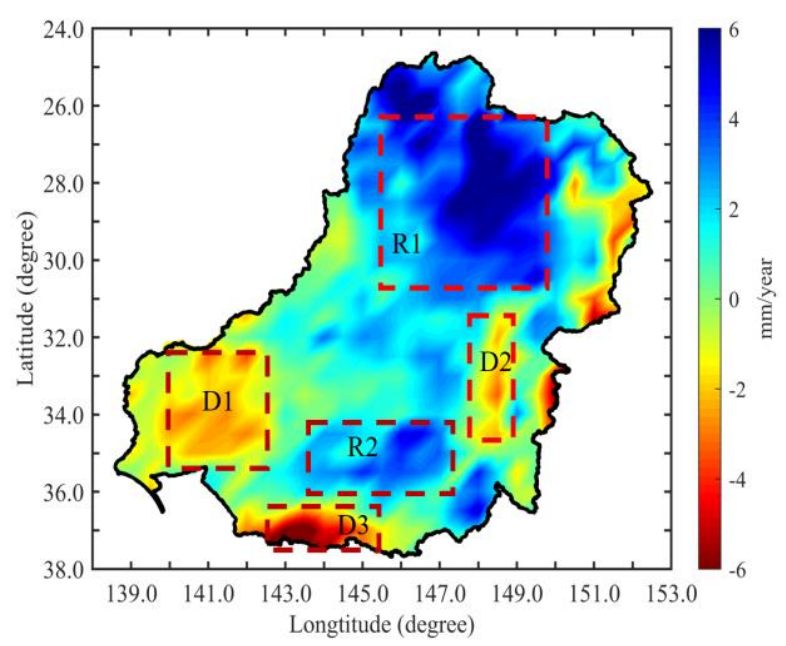

Fig.3. The spatial distribution of GWS trends over MDB from 2003 to 2015.

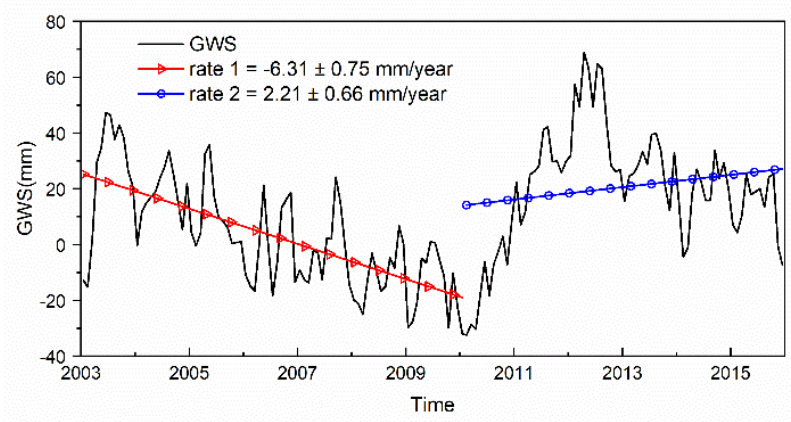

Fig.4. Time series of average GWS for the whole study area from 2003 to 2015.

\section{Conclusion}

Groundwater storage variations are estimated by using GRACE data and CABLE models over MDB from 2003 to 2015. The main conclusions are summarized as follows:

(1) The simulations of TWS from CABLE are proved to be more accurate than GLDAS, therefore, we suggest readers consider applying CBALE to some hydrological researches.

(2) In terms of spatial scale, GWS variations indicate that increasing trends can be found in the north and south central, and downward trends emerge in the southwest, east and south.

(3) The GWS variations over whole MDB experiences an obvious decreasing trend during 2003 to 2010 with a rate of $-6.31 \pm 0.75 \mathrm{~mm} /$ year and an increasing trend of $2.21 \pm 0.66 \mathrm{~mm} /$ year in recent years. For the whole period 2003-2015, GWS variations shows an increasing trend with a rate of $1.19 \pm 0.41$.

\section{References}

1. J. L. Chen, J. Li, Z. Z. Zhang, S. N. Ni, Long-term groundwater variations in Northwest India from satellite gravity measurements. Glob. Planet. Change. 116, 130 (2014).

2. B. D. Tapley, B. Srinivas, J. C. Ries, P. F. Thompson, M. M. Watkins, GRACE measurements of mass variability in the Earth system. Science 305, 503 (2004).

3. F. W. Landerer, S. C. Swenson, Accuracy of scaled GRACE terrestrial water storage estimates. Water Resour. Res. 48, 11 (2012).

4. B. R. Scanlon, Z. Zhang, H. Save, A. Y. Sun, H. Muller Schmied, L. P. H. van Beek, D. N. Wiese, Y. Wada, D. Long, R. C. Reedy, L. Longuevergne, P. Doll, M. F. P. Bierkens, Global models underestimate large decadal declining and rising water storage trends relative to GRACE satellite data. Proc. Natl. Acad. Sci. U. S. A. 115, E1080 (2018).

5. M. Rodell, J. Chen, H. Kato, J. S. Famiglietti, J. Nigro, C. R. Wilson, Estimating groundwater storage changes in the Mississippi River basin (USA) using GRACE. Hydrogeol. J. 15, 159 (2006).

6. W. Feng, M. Zhong, J. M. Lemoine, R. Biancale, H. T. Hsu, J. Xia, Evaluation of groundwater depletion in North China using the Gravity Recovery and Climate Experiment (GRACE) data and groundbased measurements. Water Resour. Res. 49, 2110 (2013).

7. F. Frappart, F. Papa, A. Guntner, J. Tomasella, J. Pfeffer, G. Ramillien, T. Emilio, J. Schietti, L. Seoane, J. D. Carvalho, D. M. Moreira, M. P. Bonnet, F. Seyler, The spatio-temporal variability of groundwater storage in the Amazon River Basin. Adv. Water Resour. 124, 41 (2019).

8. E. A. Kowalczyk, L. Stevens, R. M. Law, M. Dix, Y. P. Wang, I. N. Harman, K. Haynes, J. Srbinovsky, B. Pak, T. Ziehn, The land surface model component of ACCESS: description and impact on the simulated surface climatology. Aust. Meteorol. Oceanogr. J. 63, 65 (2013).

9. Y. P. Wang, E. Kowalczyk, R. Leuning, G. Abramowitz, M. R. Raupach, B. Pak, E. van Gorsel, A. Luhar, Diagnosing errors in a land surface model (CABLE) in the time and frequency domains. J. Geophys. Res.-Biogeosci. 116, 18 (2011).

10. H. Q. Zhang, B. Pak, Y. P. Wang, X. Y. Zhou, Y. Q. Zhang, L. Zhang, Evaluating Surface Water Cycle Simulated by the Australian Community Land Surface Model (CABLE) across Different Spatial and Temporal Domains. J. Hydrometeorol. 14, 1119 (2013).

11. N. Tangdamrongsub, S. C. Han, M. Decker, I. Y. Yeo, H. Kim, On the use of the GRACE normal equation of inter-satellite tracking data for estimation of soil moisture and groundwater in Australia. Hydrol. Earth Syst. Sci. 22, 1811 (2018).

12. M. Leblanc, S. Tweed, G. Ramillien, P. Tregoning, F. Frappart, A. Fakes, I. Cartwright, Groundwater change in the Murray basin from long-term in-situ monitoring and GRACE estimates. CRC.Press., (2012).

13. M. Schumacher, E. Forootan, A. van Dijk, H. Mueller Schmied, R. S. Crosbie, J. Kusche, P. Doll, Improving drought simulations within the Murray-Darling Basin by combined calibration/assimilation of GRACE data 
into the WaterGAP Global Hydrology Model. Remote Sens. Environ. 204, 212 (2018).

14. H. Save, S. Bettadpur, B. D. Tapley, High-resolution CSR GRACE RL05 mascons. J. Geophys. Res.-Solid Earth 121, 7547 (2016).

15. B. R. Scanlon, Z. Zhang, H. Save, D. N. Wiese, F. W. Landerer, D. Long, L. Longuevergne, J. Chen, Global evaluation of new GRACE mascon products for hydrologic applications. Water Resour. Res. 52, 9412 (2016).

16. A. M. Ukkola, A. J. Pitman, M. Decker, M. G. De Kauwe, G. Abramowitz, J. Kala, Y. P. Wang, Modelling evapotranspiration during precipitation deficits: identifying critical processes in a land surface model. Hydrol. Earth Syst. Sci. 20, 2403 (2016).

17. M. Decker, Development and evaluation of a new soil moisture and runoff parameterization for the CABLE LSM including subgrid-scale processes. J. Adv. Model. Earth Syst. 7, 1788 (2015).

18. M. Rodell, P. R. Houser, U. Jambor, J. Gottschalck, K. Mitchell, C. J. Meng, K. Arsenault, B. Cosgrove, J. Radakovich, M. Bosilovich, J. K. Entin, J. P. Walker, D. Lohmann, D. Toll, The Global Land Data Assimilation System. BAMS. 85, 381 (2004).

19. P. Yang, J. Xia, C. S. Zhan, Y. F. Qiao, Y. L. Wang, Monitoring the spatio-temporal changes of terrestrial water storage using GRACE data in the Tarim River basin between 2002 and 2015. Sci. Total Environ. 595, 218 (2017)

20. A. S. Richey, B. F. Thomas, M. H. Lo, J. T. Reager, J. S. Famiglietti, K. Voss, S. Swenson, M. Rodell, Quantifying renewable groundwater stress with GRACE. Water Resour. Res. 51, 5217 (2015).

21. P. Moore, S. D. P. Williams, Integration of altimetric lake levels and GRACE gravimetry over Africa: Inferences for terrestrial water storage change 20032011. Water Resour. Res. 50, 9696 (2014). 